$\xi_{p}$

\title{
Behavioural Study on Self Curing Concrete Using Poly Ethylene Glycol and Silica Fume
}

\author{
Dr. T. Senthil Vadivel ${ }^{1}$, E. Giri Prasad Goud ${ }^{2}$, S. Nagarjuna ${ }^{2}$, M. Doddurani ${ }^{3}$ and A.P. Geethu ${ }^{4}$ \\ ${ }^{1}$ Professor \& Head, Department of Civil Engineering, School of Engineering \& Technology, Adamas University, Kolkata - 700126. \\ West Bengal. Email: tsnsenthu@ rediffmail.com \\ ${ }^{2}$ Assistant Professor, Department of Civil Engineering, Vidya Jyothi Institute of Technology, Hyderabad - 500075. Telangana. \\ Email: giriprasadgoud7@gamil.com,nagarjunacivil.somineni@gmail.com \\ ${ }^{3}$ Assistant Engineer, PWD - WRD, Upper Cauvery Basin Circle, Salem-636007.Tamilnadu. Email: mallaiahrani@gmail.com \\ ${ }^{4}$ Post Graduate Student, Department of Civil Engineering, RVS Technical Campus, Coimbatore-641402. Tamilnadu, India.
}

\begin{abstract}
-
Water has a major role throughout the life of the concrete, because it is a critical component in the mixing, curing and hardening. Water obtained by the curing of concrete maintains satisfactory moisture content in order to achieve the desired properties developing the concrete microstructure and pore structure and hence improves its durability and performance. But, good curing is not always practical in many cases. So attempts have been made to develop internal curing concrete in which internal - curing agent provides water internally which is distributed throughout the concrete matrix whereas plain concrete is completely dependent on surface curing which only penetrates concrete surface by a few millimeter. Keeping importance to this, an attempt has been made to develop internal-curing concrete by using Poly Ethylene Glycol (PEG-400). In this experimental analysis the strength characteristics of conventional concrete and self curing concrete, cast with the selfcuring agent PEG-400 have been studied and compared. M30 grade of concrete is adopted using IS method of mix design. For the production of internal-curing concrete trial fractions of $1 \%, 2 \%$ and $3 \%$ of PEG-400 and silica fume of $15 \%, 18 \%$ and $20 \%$ by weight of cement was used and tested for different mechanical properties and found that $1 \%$ PEG at $20 \%$ silica fume is the optimal among all mixes.
\end{abstract}

Keywords-Internal curing agent, Poly Ethylene Glycol, Moisture Content, Shrinkage, Mechanical Properties.

\section{Introduction}

Water is an essential component, the quantity of which in concrete determines fresh and hardened properties of concrete including workability, initial- final setting time, compressive strength, flexural strength, durability, weathering, drying shrinkage and potential for cracking. For these reasons, limiting and controlling the amount of water in concrete is important for both construction and service life. Obtaining that control of the water is observed as one of the key considerations in concrete technology. Minimum amount of water is needed to achieve the required rheological properties of the various concrete materials in their mixing, transporting, placing and compacting, and to hydrate cement. On the other hand, with the increased free water content the chances of segregation and bleeding of fresh concrete increases. Moreover, it leads to the porosity of the hardened concrete and accordingly to considerable reduction in mechanical properties, durability and increased shrinkage and creep deformations.

Curing maintains satisfactory moisture content in order to attain the desired properties and it is one of the most important necessities for optimum concrete performance. However, good curing is not always practical in many cases. Therefore, the technique of using self-curing agents will be a good alternative. In conventional curing method, all the properties and strength of concrete is achieved by external curing applied after mixing and casting. Self-curing or internal curing is a technique that can be used to provide additional moisture in concrete for more effective hydration of cement and reduced self-desiccation. So the use of self-curing admixtures is very significant from the point of control of water. Wen-Chen Jau (2011) explained that the selfcuring concrete absorbs water from air and moisture to process the hydration of cement. It gives better solution for the cement hydration when it becomes lower at the time of improper or no curing by using poly acrylic acid as self curing agent which will absorb atmospheric moisture and gives enough water for curing. Mateusz Wyrzykowski et. al. (2012) prepared a model for water movement at the time of internal curing with super absorbent polymer (SAP). SAP will distribute evenly in the concrete and act as water absorbent which absorb water during mixing and release it during the time of hydration to the cement paste. Using SAP we can provide curing with low water cement ratio mixtures also. John Roberts et. al. (2013) demonstrated internal curing improves flexural and compressive strength of pervious concrete. Roland Tak Yong Liang, Robert Keith Sun (2002) conducted experiment for self curing concrete using glycol \& wax. It reports the first internal curing composition for concrete or other cementitious mixes and meets the AS 3799 standards. Sathanandham T et. al. (2013) in their study mentioned that the addition of polyethylene glycol (PEG) in plain cement concrete lead in to shrinkage and 
affects the durability. Hence they suggested it is essential to introduce some shrinkage reducing admixture to improve durability. Siddiqui M. Junaid et. al. (2015) presented the use of shrinkage reducing admixture i.e. polyethylene glycol (By adding $1 \% \& 1.25 \%$ of PEG-4000 by weight of cement) in M40 grade of concrete (Grade ratio $=1: 2.23: 3.08$ ) which helps in self-curing with better hydration which reduces shrinkage cracks and hence increases strength and is compared with that of conventional cured concrete of the same grade.

\section{Materials and Methods}

\section{A. Fine Aggregate}

Fine aggregate used for the study should be properly graded to give the minimum voids ratio and shall be free from harmful materials like clay, silt content and chloride contamination. River sand is normally preferred over crushed sand since in the former particle shape is fully water worn by attrition which helps in reduction of water content of mix and also lesser resistance to be pumped. Selected Fine aggregate is locally available river sand conforming to Grading zone II of IS 383-1970. Weight of sample is $200 \mathrm{~g}$.

Table 1. Properties Of Fine Aggregate

\begin{tabular}{|c|c|}
\hline Fineness modulus & $2.25 \%$ \\
\hline Specific gravity & 2.60 \\
\hline Water absorption & $1 \%$ \\
\hline
\end{tabular}

\section{B. Coarse Aggregate}

The coarse aggregate is the strongest and the least porous component of concrete. Some important properties of coarse aggregate like crushing strength, gradation and bulk density need special consideration while selecting the coarse aggregate. Crushed granite aggregate with a maximum nominal size of $20 \mathrm{~mm}$ have been used. A summary on properties of coarse aggregate are given below as per code IS 2386 \& 383-1970. Weight of sample is $200 \mathrm{~g}$.

Table 2. Properties of Coarse Aggregate

\begin{tabular}{|c|c|}
\hline Specific gravity & $6.05 \%$ \\
\hline Water absorption & 2.60 \\
\hline
\end{tabular}

\section{Cement}

Ordinary Portland Cement is used throughout this investigation. The important properties of the cement are given below.

Table 3. Properties of Cement

\begin{tabular}{|c|c|}
\hline Grade of Cement used & $\begin{array}{c}\text { Ordinary } \\
\text { Portland Cement, } \\
\mathbf{5 3} \text { grade }\end{array}$ \\
\hline Specific Gravity of Cement & 3.15 \\
\hline Fineness of cement & $3 \%$ \\
\hline Initial setting time & $28 \mathrm{~min}$ \\
\hline Final setting time & $310 \mathrm{~min}$ \\
\hline
\end{tabular}

\section{Water}

Water conforming to the requirements of IS 456-2000 is found to be suitable for making concrete it is generally stated that water fit for drinking is fit for making concrete. For this present investigation, drinking water supplied to Coimbatore city was used for making concrete.

\section{E. Polyethylene Glycol (PEG 400)}

Polyethylene glycol is a condensation polymer of ethylene oxide and water used in this study for internal curing. Oxy-ethylene groups typically from 4 to about 180 and notates with an abbreviation PEG. Polyethylene Glycol is non-toxic, odourless, neutral, lubricating, non-volatile and non-irritating and is used in a variety of pharmaceuticals. One common feature of PEG appears to be the water-soluble nature. PEG in concrete forms a shell structure around the water molecules and control evaporation and makes water available throughout the period of hydration and reduces early shrinkage. Since evaporation is not happened, no need of extra water for curing, henceforth it is called as self curing agent in this research.

\section{F. Super plasticizer}

CONPLAST SP430 is a chloride free, super plasticizing admixture supplied as a brown solution which instantly disperses in water. It provides excellent strength at early ages and durability by significantly reducing water demand in a concrete mix. CONPLAST is particularly suitable for precast concrete and other high early strength requirements. It improves the workability of site mixed and precast concrete without increasing water demand and provide improved durability by increasing ultimate strengths and reducing concrete permeability. It makes possible major reductions in water cement ratio which allow the production of high strength concrete without excessive cement contents.

\section{G. Silica Fume}

Silica Fume is an amorphous silicon dioxide contains extremely small particles than the cement. It produced in electric furnace when silicon metal and alloy in operation, resulted smoke and deposited in the furnace. Since this fume is very fine and cover large surface area with high siliceous content, is used as reactive pozzolan in this study.

\section{Experimental Programme}

The speculated grade for the respective mix design is M30 with a total cement weight of $380 \mathrm{Kg} / \mathrm{m} 3$, sand weight of $711 \mathrm{Kg} / \mathrm{m} 3$ and an aggregate weight of $1283 \mathrm{Kg} / \mathrm{m} 3$. The maximum nominal size of aggregates is $20 \mathrm{~mm}$. The specified water cement ratio for the experiment is 0.40. Admixtures used in this experiment include chemical admixtures such as PEG400 and CONPLAST and mineral admixtures such as silica fume. The specified mix ratio is 1: $1.87: 3.37$.

An Ordinary Portland Cement with specific weight $3.12 \mathrm{~g} / \mathrm{cm} 3$, specific surface $3000 \mathrm{~cm} 2 / \mathrm{g}$ and silica fumes are used in powder form with silica ( $\mathrm{SiO} 2)$ of $95 \%$, silicious sand as a fine aggregate (with fineness modulus of 2.79), and gravel as a coarse aggregate of nominal maximum size $(20 \mathrm{~mm})$ from quarry were used. The super plasticizer (SP) used was CONPLAST 430 of $0.5 \%$. This is of the sulphated naphthalene formaldehyde condensate type. The super plasticizer dosage was adjusted to produce concretes with the same slump of $120+/-10 \mathrm{~mm}$ and do not show the visual signs of segregation during the normal casting of concrete in the moulds. The chemical agents of Polyethylene-Glycol of characteristics as produced by the manufacture and used as selfcuring agent. This investigation includes testing of cubes, cylinders and prisms of conventional concrete and self curing concrete. Our specimens are divided into nine mixes namely M1, M2, M3, M4, M5, M6, M7, M8 and M9 as outlined. The specimens were differed in percentage of silica fume \& polyethylene glycol added in it by the weight of cement. The specimen details are given in Table 4. 
Table 4. Specimen Details

\begin{tabular}{|c|c|c|c|c|}
\hline $\begin{array}{l}\text { Sl. } \\
\text { No. }\end{array}$ & Description & $\begin{array}{l}1 \% \\
\text { PEG }\end{array}$ & $3 \%$ PEG & $\begin{array}{c}5 \% \\
\text { PEG }\end{array}$ \\
\hline 1 & $15 \%$ Silica Fume & MIX 1 & MIX 2 & MIX 3 \\
\hline 2 & $18 \%$ Silica Fume & MIX 4 & MIX 5 & MIX 6 \\
\hline 3 & $20 \%$ Silica Fume & MIX 7 & MIX 8 & MIX 9 \\
\hline
\end{tabular}

In a similar manner the other mixes were cast. Every mix consists of 9 cubes, 9 cylinders and 9 prisms for compressive strength test, split tensile test and flexural test respectively. Totally 270 specimens are casted for testing. ie, Three replicate specimens were tested at each test age for each type of mixture. Cubes are of nominal size $150 \times 150 \times 150 \mathrm{~mm}$, cylinders using in this area of height $300 \mathrm{~mm}$ and diameter $150 \mathrm{~mm}$ and prisms have a size of $500 \times 100 \times 100 \mathrm{~mm}$ were tested.M30 Grade of concrete is used for testing the specimens. After casting all the specimen were kept in room temperature to carry out internal curing by PEG and testing is done for 7 th day, 14th day and 28th day curing.

\section{Results and Discussion}

\section{A. Slump Test}

Slump test were performed to assess concrete workability. Table 5 shows the results of Slump test. Almost all the slumps are workable in nature and the results are very close to each other.

Table 5. Slump Test Results

\begin{tabular}{|c|c|}
\hline Mix ID & Slump Value (mm) \\
\hline Mix 1 & 85 \\
\hline Mix 2 & 81 \\
\hline Mix 3 & 78 \\
\hline Mix 4 & 80 \\
\hline Mix 5 & 75 \\
\hline Mix 6 & 73 \\
\hline Mix 7 & 74 \\
\hline Mix 8 & 70 \\
\hline Mix 9 & 69 \\
\hline
\end{tabular}

\section{B. Mechanical Properties of Hardened Concrete Specimens}

The addition of the PEG to the concrete mixtures has beneficial effects on the mechanical properties of hardened concrete. The effect of volume of silica fume on the mechanical properties such as compressive strength, split tensile strength and flexural strength at different test ages are reported.

\section{Compression Tests Results}

The compressive strength tests were performed on one conventional concrete and self curing concrete cube specimen. The nine different mixtures of [PEG400] 1\%, 3\%, 5\% and silica fume $15 \%, 18 \%, 20 \% \& 0.5 \%$ of CONPLAST SP 430 respectively were prepared. These were tested at the stages of 7 , 14 and 28 days using compression testing machine of $2000 \mathrm{kN}$ capacity as per BIS 516-1959. Three replicate specimens were tested at each test age for each type of mixture.

\section{Split-Tensile Test Results}

The splitting tensile tests were performed on one conventional concrete and self curing concrete cylinder specimen. Using compression testing machine of $2000 \mathrm{kN}$ capacity as per BIS $5816-1970$ this test set up is done for the splitting tensile strength on the cylinder specimen with two cast-iron strips to avoid the direct load on the specimen. Three replicate specimens were tested at each test age for each type of mixture.

\section{E. Flexural Test Results}

The flexural strength tests were performed on one conventional concrete and self curing concrete prism specimen. The nine different mixtures were, [PEG400] 1\%, 3\%, 5\% and silica fume $15 \%, 18 \%, 20 \% \& 0.5 \%$ of CONPLAST SP 430 respectively by volume of cement. These were tested at the stages of 7, 14 and 28 days using $100 \mathrm{kN}$ capacity flexural strength testing machine by subjecting the specimen to two point loading to determine the flexural strength as per BIS 516-1959. Three replicate specimens were tested at each test age for each type of mixture.

\section{F. Comparison of Compressive Strength Test Result with} Conventional and SCC

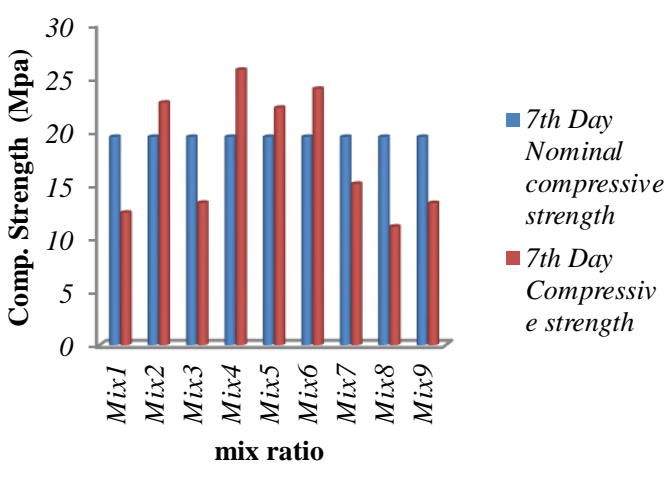

Fig. 1. $7^{\text {th }}$ day Compression test result

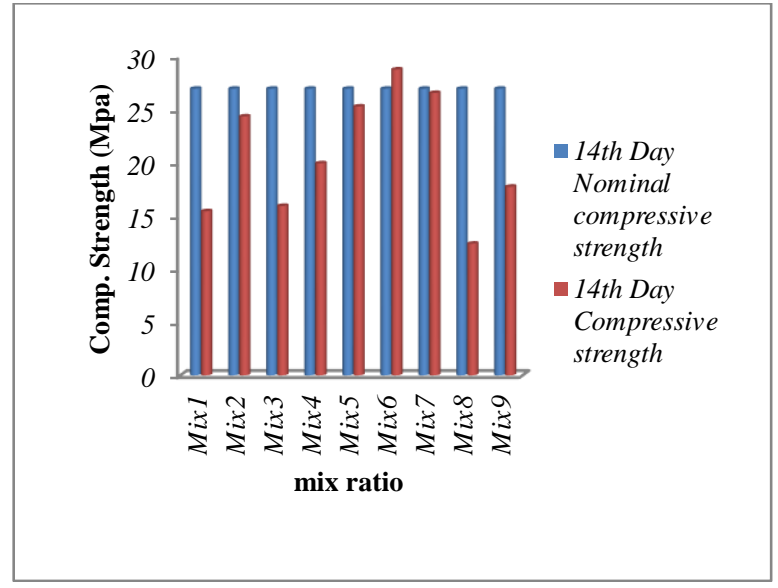

Fig. 2. $14^{\text {th }}$ day Compression test result

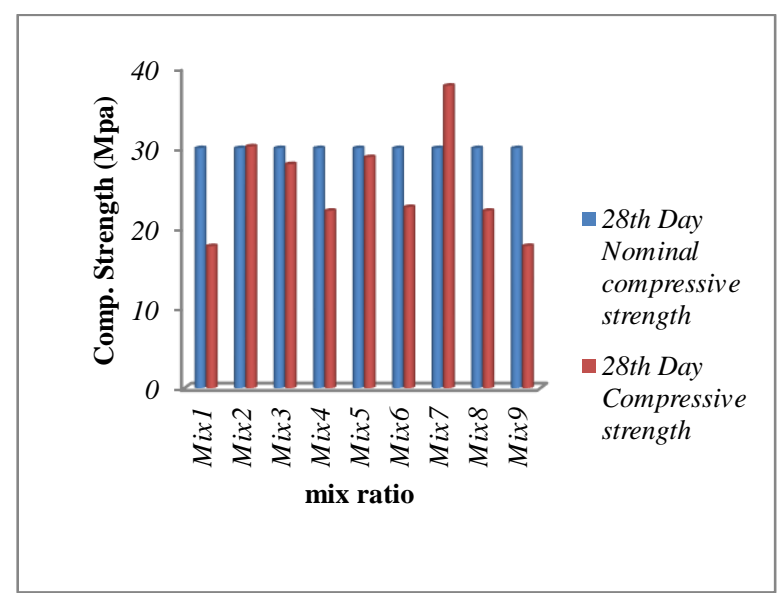


Fig. 3. $28^{\text {th }}$ day Compression test result

G. Comparison of Split Tensile Test Results with Conventional and SCC

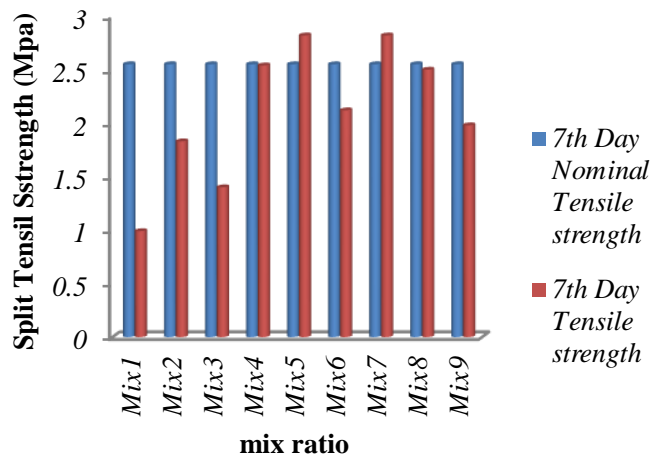

Fig. 4. $7^{\text {th }}$ day Split Tensile test result

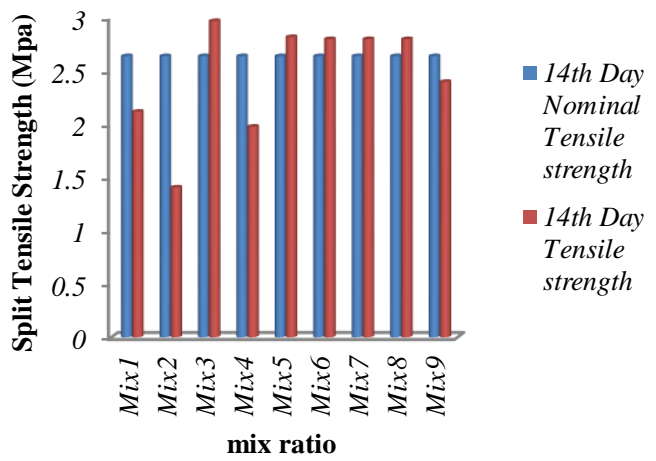

Fig. 5. $14^{\text {th }}$ day Split Tensile test result

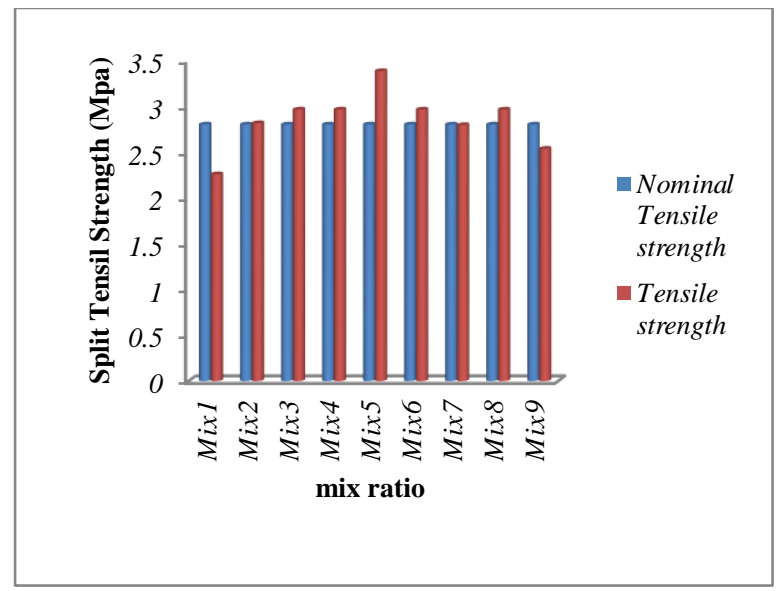

Fig. 6. $28^{\text {th }}$ day Split Tensile test result

$H$. Comparison of Flexural Strength Test Results with Conventional and SCC

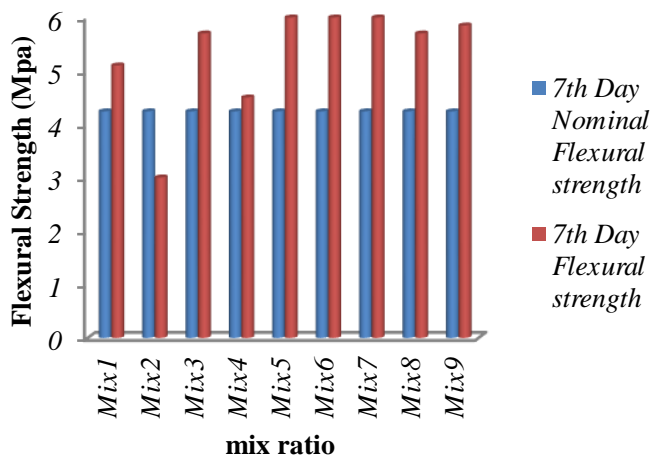

Fig. 7. $^{\text {th }}$ day Flexural test result

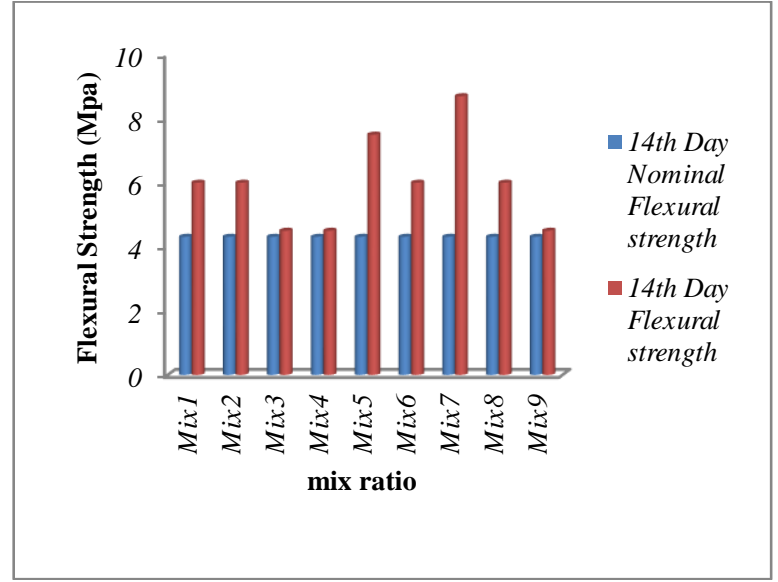

Fig. 8. $14^{\text {th }}$ day Flexural test result

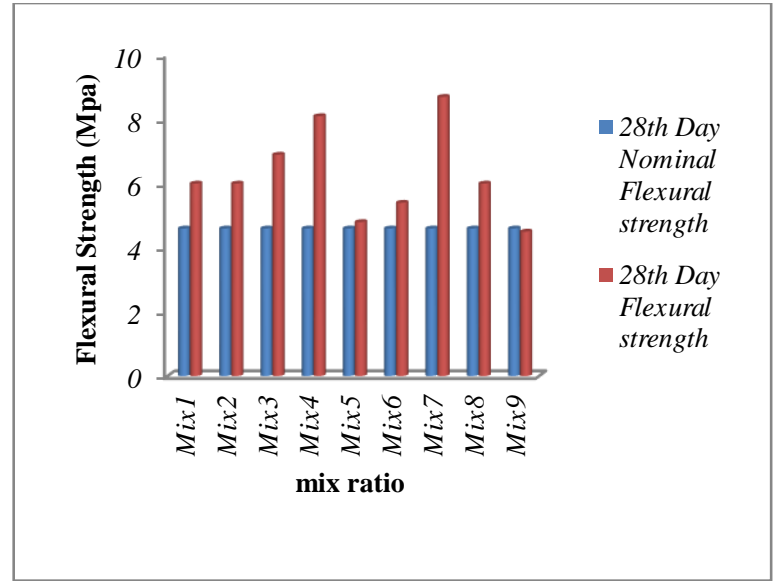

Fig. 9. $28^{\text {th }}$ day Flexural test result

\section{Conclusion}

Based on the abovementioned study following conclusions has been derived:

- Polyethylene Glycol was found to be more effective self curing agent and it improves workability. 
- The optimum percentage fraction for PEG 400 for compressive strength is found to be $1 \%$ Polyethylene Glycol and $20 \%$ silica fume.

- The optimum percentage fraction for PEG 400 for Split Tensile strength is found to be 3\% Polyethylene Glycol and $18 \%$ silica fume.

- The optimum percentage fraction for PEG 400 for Flexural strength is found to be $1 \%$ Polyethylene Glycol and $20 \%$ silica fume.

- The optimum percentage fraction PEG400 for all mechanical properties is found to be $1 \%$ at $20 \%$ silica fume usage.

\section{References}

[1] Wen-Chen Jau, "Methods for self-curing concrete", IFI claims patent Services, 16 August 2011.

[2] Mateusz Wyrzykowski, Pietro Lura, Francesco Pesavento and Dariusz Gawin, "Modelling of Water Migration during Internal Curing with Superabsorbent Polymers," Journal of Materials in Civil Engineering, 2012.

[3] John Roberts and Ron Vaughn, "Internal Curing Improves Flexural and Compressive Strength Of Pervious Concrete," Northeast Solite Corporation Saugerties, New York, 2013.

[4] Roland Tak Yang Liang and Robert Keith Sun, "Compositions and Methods for curing concrete," Also published as CA2308237A1, Australian Standard AS 3799, 22 October 2002.

[5] T. Sathanandham, R. Gobinath, M. Naveen Prabhu,

Gnanasundar, K. Vajravel, G. Sabariraja, R. Manoj kumar and R. Jagathishprabu, "Preliminary Studies of Self Curing Concrete with the Addition of Polyethylene Glycol," International Journal of Engineering Research \& Technology (IJERT) Vol. 2 Issue 11, 2013.

[6] Siddiqui Mohd. Junaid, Sheikh Saddam, Khan Yusuf, Shaikh Abu Huzaifa and Mansuri Junaid, "Study the use of shrinkage reducing admixture (PEG4000) for M40 grade concrete which attained more strength than conventional cured concrete," Journal Of Civil Engineering and Environmental Technology (JCEET) Vol. 2, Number 6 April 2015. 